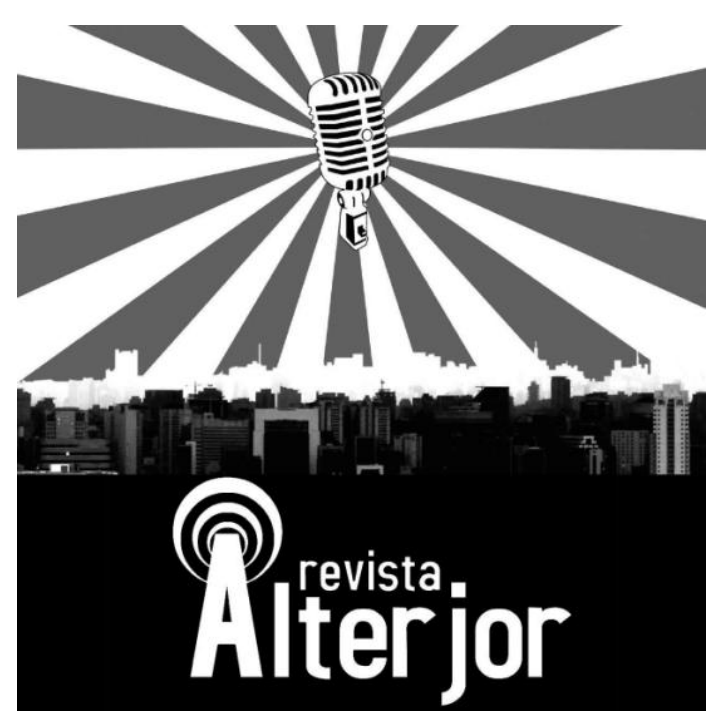

DOSSlê: "Comunicação nas Periferias"

\title{
JORNALISTAS DE QUEBRADA: \\ A PERIFERIA EM MOVIMENTO ENQUANTO ESPAÇO DE CONSTRUÇÃO DE SUJEITOS COMUNICACIONAIS
}

\author{
Thiago de Souza Borges ${ }^{1}$ \\ Aline Rodrigues da Silva ${ }^{2}$ \\ Laís Diogo Costa $^{3}$ \\ Camila Lima Cerqueira ${ }^{4}$
}

\begin{abstract}
RESUMO: Criada em 2009 a partir do trabalho de conclusão de curso de jovens jornalistas que moram em periferias da zona Sul da cidade de São Paulo (SP), a Periferia em Movimento completa mais de uma década de atuação produzindo conteúdo jornalístico sobre garantia de direitos elaborando novas narrativas possíveis a partir das ações sociais, culturais e políticas das margens da capital paulista. E, para além de repensar o fazer jornalístico em si, tem formado e transformado os próprios "Jornalistas de Quebrada" como os autores e integrantes da iniciativa demonstram neste relato de experiência.
\end{abstract}

PALAVRAS-CHAVE: Jornalismo de Quebrada. Jornalismo Periférico. Periferias. Comunicação periférica.

\footnotetext{
${ }^{1}$ Jornalista pela Universidade Santo Amaro (Unisa) com Especialização em História, Sociedade e Cultura pela Pontifícia Universidade Católica de São Paulo (PUC-SP). E-mail: thisbo@gmail.com

2 Jornalista pela Universidade Santo Amaro (Unisa). E-mail: alinereporter84@gmail.com

${ }^{3}$ Estudante de Serviço Social pela Universidade Santo Amaro (Unisa). E-mail: laisdiogo26@gmail.com

${ }^{4}$ Estudante de Jornalismo pela Universidade Anhembi Morumbi. E-mail: camila.limac@ @otmail.com
}

Revista ALTERJOR

Grupo de Estudos Alterjor: Jornalismo Popular e Alternativo (ECA-USP)

Ano 10 Volume ol Edição 23 Janeiro-Julho de 202l

Avenida Professor Lúcio Martins Rodriģues, 443, Cidade Universitária, São Paulo, CEP: 05508-020 
ABSTRACT: Founded in 2009 during the conclusion research by young journalists who live on the outskirts of the south area of the city of São Paulo (SP), Periferia em Movimento completes more than a decade of activity producing journalistic content about guaranteeing rights elaborating new possible narratives based on social, cultural and political actions on the margins of the São Paulo capital. And, in addition to rethinking newsmaking itself, it has trained and transformed the "Jornalistas de Quebrada" themselves as the authors and members of the initiative demonstrate in this report.

KEYWORDS: Alley journalism. Peripheral Journalism. Peripheries. Peripheral communication. Jornalistas de Quebrada.

\section{QUEM SOMOS NÓS, AFINAL?}

Nós somos a Periferia em Movimento ${ }^{5}$, produtora independente que desde 2009 discute e produz um Jornalismo de Quebrada (Souza, 2015) - feito sobre, para e a partir das margens da cidade, que busca combater estereótipos e ampliar a representatividade das periferias na mídia com objetivo de construir uma sociedade sem racismo, machismo e LGBTfobia. A iniciativa surge a partir de um trabalho de conclusão do curso de Jornalismo na Universidade Santo Amaro (Unisa), com pesquisa sobre a representação midiática das periferias urbanas ${ }^{6}$.

A Periferia em Movimento parte da articulação no território para pensar pautas jornalísticas em diferentes formatos, considerando a garantia de direitos, as memórias e identidades dos sujeitos retratados, bem como seu protagonismo na narrativa e a busca pela ocupação dos espaços de poder. As trocas culturais contínuas com entrevistados consistem num processo pedagógico que se transforma em conteúdo jornalístico.

Neste relato de experiência, apresentamos como a Periferia em Movimento é laboratório de experimentações e de formação desses jornalistas de quebrada, sujeitos

\footnotetext{
${ }^{5}$ Disponível em: http://periferiaemmovimento.com.br Acesso em 03 nov. 2020.

${ }^{6}$ Disponível em: https://drive.google.com/drive/u/0/folders/0B3JCxh9_wbQkYWMwbzN2bWNPc0E. Acesso em 03 nov. 2020.
}

Revista ALTERJOR

Grupo de Estudos Alterjor:Jornalismo Popular e Alternativo (ECA-USP)

Ano 10 Volume Ol Edição $23 \quad$ Janeiro-Junho de 202l

Avenida Professor Lúcio Martins Rodrig̉ues, 443, Cidade Universitária, São Paulo, CEP: 05508-020 


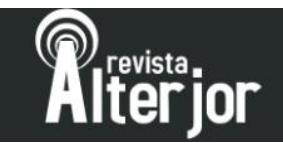

comunicacionais e periféricos em diálogo constante com os territórios, as pessoas e consigo próprios.

\section{O QUE NOS MOVE}

\section{1. O TERRITÓRIO COMO DISPARADOR DAS NARRATIVAS}

Um pé de mandioca brava continua crescendo na praça que fica em frente à sede da redação da Periferia em Movimento. Embaixo desse pé, corre um rio canalizado que nasce no Alto da Alegria ${ }^{7}$, uma favela com mais de 40 anos que hoje está em processo de urbanização, e deságua em um dos braços da represa Billings. Crianças jogam bola na grama, adultos descansam na hora do almoço, casais namoram e jovens se reúnem para ouvir funk e conversar.

Mananciais, natureza, ocupações irregulares, convivência, cultura e resistência. Está tudo ali. As cenas cotidianas podem ser observadas da janela e dão base para o trabalho da Periferia em Movimento a partir desse lugar. É importante ressaltar que esse jornalismo não é local, mas territorializado. E o geógrafo Milton Santos (1999) nos ensina que "território" é o chão mais a identidade, ou seja: não é só o chão em que a gente pisa, mas o conjunto das relações sociais, econômicas, artísticas, afetivas que estabelecemos a cada passo que damos.

A Periferia em Movimento tem como centro a rua Ezequiel Lopes Cardoso. O território é disparador de práticas enquanto jornalistas de quebrada. Portanto, é importante situar de que lugar, partimos. O local era apenas utilizado por indígenas Guarani Mbya como passagem entre o litoral e o planalto paulista (Martins, 2003), com vias terrestres e fluviais que ligavam as aldeias de Ibirapuera e Itanhaém. Em 1829, a região começou a ser efetivamente ocupada com a chegada de 229 colonos alemães onde hoje fica o bairro de Colônia Paulista (Parelheiros), e a posterior chegada de imigrantes japoneses, italianos e portugueses. (Ribeiro, 1997 apud Martins, 2003).

\footnotetext{
${ }^{7}$ Em 2018, a Periferia em Movimento produziu a reportagem "Extremo Sul: um reservatório de tensões entre as represas Billings e Guarapiranga" sobre os conflitos entre direito à moradia e a preservação ambiental no Extremo Sul da cidade de São Paulo. A favela Alto da Alegria foi um dos locais retratados. Disponível em: http://periferiaemmovimento.com.br/reservatorio-de-tensoes-o-documentario/. Acesso em 03 nov. 2020
}

Revista ALTERJOR

Grupo de Estudos Alterjor:Jornalismo Popular e Alternativo (ECA-USP)

Ano 10 Volume Ol Edição 23 Janeiro-Junho de 2021 Avenida Professor Lúcio Martins Rodrig̉ues, 443, Cidade Universitária, São Paulo, CEP: 05508-020 


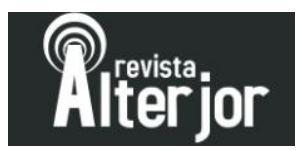

Nas últimas cinco décadas, esse lugar foi ocupado por migrantes de outras regiões brasileiras. No subdesenvolvimento desindustrializado, a casa própria é fator primordial de sobrevivência e estabilidade, como recordou Lucio Kowarick (2009). O preço da terra subiu $150 \%$ entre 1950 e 1980, o transporte ficou mais caro, o desemprego cresceu e não tinha dinheiro pra financiar moradia: muitos moradores vieram para favelas ou regiões onde não se poderia construir, como as áreas de proteção aos mananciais (Kowarick, 2009).

Em 1976, o Governo do Estado publicou a Lei de Proteção aos Mananciais. Com objetivo de impedir a comercialização de terras nas bacias hidrográficas dos dois reservatórios, a lei teve efeito contrário: derrubou o preço das terras. Sem fiscalização, proprietários e grileiros lotearam terrenos e venderam muito barato a milhares de trabalhadores que chegavam de outras localidades (Silva, 2011).

Atualmente, a região do Grajaú apresenta população formada predominantemente por jovens. De acordo com o Mapa da Desigualdade $2019^{8}$ da Rede Nossa São Paulo, também detém a segunda maior proporção de negros entre os distritos da capital paulista $(56,8 \%)$. Por outro lado, a idade média ao morrer dessa população está entre as piores do município: 58 anos, acima apenas de Marsilac e Cidade Tiradentes, com 57. Em média, um morador do Grajaú vive 22 anos a menos do que quem vive em Moema. Esse índice é marcado por taxas de homicídio, violência no trânsito, como também por violações constantes na saúde, educação e outras áreas.

Se não garante direitos de um lado, por outro lado o poder público busca gerir as margens para não afetar o abastecimento de água no restante da metrópole (Feltran, 2001). Com iniciativas como "Programa Mananciais" e “Operação Defesa das Águas", desde meados dos anos 2000 tanto Prefeitura quanto Governo do Estado investem em projetos de urbanização de bairros (Silva, 2011). Até 2014, o Grajaú tinha 17.000

\footnotetext{
${ }^{8}$ Disponível em: https://www.nossasaopaulo.org.br/campanhas/\#13 - Acesso em: 23 jan 2020.
} 


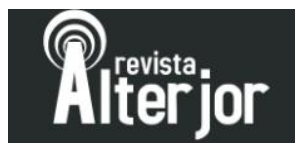

moradias em 74 favelas (4,44\% do total do município) - em 2000, 22 mil casas estavam em aglomerados $(6,44 \% \text { da cidade })^{9}$.

A população da Capela do Socorro (subprefeitura em que fica o Grajaú) cresceu 10.000\% entre os anos 1950 e 2010, de 6,1 mil para 594 mil pessoas, segundo o Infocidade da Prefeitura de São Paulo ${ }^{10}$. A projeção para o futuro é de estabilidade: em 2040, a região deve ter essa mesma população. Enquanto isso, a mancha urbana aumenta de tamanho sobre áreas de proteção ambiental: o distrito de Parelheiros, que tinha 31 mil habitantes em 1980 e chegou a 131 mil em 2010, deve alcançar a marca de 236 mil moradores até 2040, segundo projeções do IBGE e da Secretaria Municipal de Desenvolvimento Urbano ${ }^{11}$.

A tendência é de perpetuação de um antigo modelo de segregação: a expansão periférica, que não acabou. Pelo contrário: aponta para fronteiras mais distantes, no Extremo Sul. E é por isso que é importante estar neste território, de maioria jovem e negra, em que os conflitos emergentes da cidade tendem a se acirrar. $\mathrm{O}$ jornalismo feito a partir dessas margens parte do local para pensar a conjuntura paulistana e de todo o País.

\subsection{PISANDO O MESMO CHÃO}

A Periferia em Movimento tem duas frentes de atuação: a produção de conteúdo jornalístico; e a articulação dos extremos ao centro de poder.

\footnotetext{
${ }^{9}$ Disponível em: http://infocidade.prefeitura.sp.gov.br/htmls/9_estimativas_de_domicilios_em_favelas_2008_10624.html. Acesso em Acesso em 03 nov. 2020.

${ }^{10}$ Disponível em: http://infocidade.prefeitura.sp.gov.br/htmls/7_populacao_censitaria_e_projecoes_populac_2008_10489.ht ml. Acesso em 03 nov. 2020.

${ }^{11}$ Disponível em: http://infocidade.prefeitura.sp.gov.br/htmls/7_populacao_censitaria_e_projecoes_populac_2008_10489.ht ml. Acesso em 03 nov. 2020.
} 


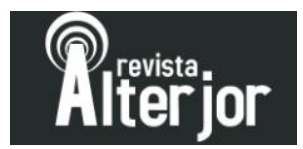

Com objetivo de ampliar a representatividade da população das periferias da cidade, a iniciativa produz e publica reportagens em textos, fotos, vídeos, mapas, podcasts, áudios de WhatsApp, transmissões ao vivo, entre outros. Os conteúdos buscam trazer como protagonistas os sujeitos periféricos à frente de lutas por garantia de direitos contra o genocídio, no âmbito do gênero e da sexualidade, pela moradia e a mobilidade na preservação do meio ambiente, pela cultura e a identidade, pela saúde e educação, pelo trabalho e renda, na terceira idade e na resistência indígena.

A internet é o principal canal de distribuição desses conteúdos, que se dá principalmente por mídias sociais, como Facebook ${ }^{12}$, Instagram $^{13}$, Twitter $^{14} \mathrm{e}$ YouTube $^{15}$, que direcionam o público para o site da Periferia em Movimento. Desde 2019, a Periferia em Movimento também publica boletins voltados especificamente para o WhatsApp ${ }^{16}$. E em 2020, começou a distribuir pílulas de conteúdo em áudio: os ZAPcasts. Esse conteúdo também é disponibilizado em plataformas como o Anchor ${ }^{17}$.

Desde 2018, a Periferia em Movimento produziu mais de 500 conteúdos, atingindo um público médio mensal de 120 mil pessoas, sendo 68\% do gênero feminino e $75 \%$ com idade entre 18 e 45 anos. A produção de conteúdo é o coração de um processo que tem a Articulação tanto como início como encaminhamento. É na articulação com os territórios, por meio de fóruns e redes, que surgem as pautas.

Essa articulação também é proposta de forma direta com a realização de encontros de aprendizagem, como oficinas, cursos e vivências sobre comunicação, direitos humanos, periferias e a cidade. Por meio da metodologia própria Repórter da Quebrada, a Periferia em Movimento promove encontros principalmente com adolescentes que estudam em escolas públicas para discutir representatividade na mídia e elaborar novos conteúdos.

\footnotetext{
12 Disponível em: http://facebook.com/periferiaemmovimento

13 Disponível em: http://instagram.com/periferiaemmovimento

14 Disponível em: http://twitter.com/perifasemove

15 Disponível em: http://youtube.com/periferiaemmovimento

16 Número de contato: +5511957816636

17 Disponível em: http://anchor.fm/periferia-em-movimento
} 


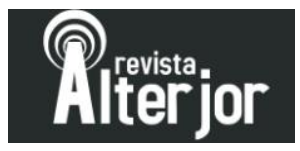

Desde 2010, foram realizadas mais de 2 mil horas de atividades com mais de 4,8 mil participantes, de forma presencial ou virtual ${ }^{18}$. Os encontros on-line ${ }^{19}$ Repórter da Quebrada registraram um alcance de mais de 2 mil acessos na internet.

O encaminhamento se dá com a discussão sobre periferias e a prática de fazer jornalismo de quebrada "da ponte pra lá" para pautar o olhar das margens na comunicação. A Periferia em Movimento é um dos coletivos fundadores da Rede Jornalistas das Periferias (2016) e do Fórum Comunicação e Territórios (2019); desde 2017, é membro do júri do Prêmio Jornalístico Vladimir Herzog de Anistia e Direitos Humanos; e já foi citada em dezenas de pesquisas e trabalhos acadêmicos ${ }^{20}$.

\section{NOSSOS APRENDIZADOS}

Nesta seção, a Periferia em Movimento traz relatos em primeira pessoa sobre aprendizados a partir de diferentes perspectivas: dois relatos dos fundadores da iniciativa, Thiago Borges e Aline Rodrigues; um relato de Laís Diogo, jovem comunicadora que participou de processos de formação e hoje integra a iniciativa; e, por último, de Camila Lima, outra comunicadora que ingressou na produtora como profissional, sem vivenciar os processos da fundação ou de formação prévia para tanto. Assim, acreditamos que conseguimos trazer um panorama mais amplo desse espaço de construção de Jornalistas de Quebrada.

\subsection{THIAGO BORGES: A CONSTRUÇÃO DO PRÓPRIO CAMINHO}

Eu me chamo Thiago de Souza Borges, tenho 33 anos e, desde que nasci, sou morador do distrito do Grajaú, no Extremo Sul de São Paulo. Sou um dos fundadores da Periferia em Movimento, onde atuo como gestor de conteúdos. Também sou editor de

\footnotetext{
18 Disponível em: http://periferiaemmovimento.com.br/videosrdq/. Acesso em 03 nov. 2020.

19 Disponível em: http://periferiaemmovimento.com.br/rdq2020/. Acesso em 03 nov. 2020.

${ }^{20}$ Disponível em: https://drive.google.com/drive/u/0/folders/0B3JCxh9_wbQkYWMwbzN2bWNPc0E. Acesso em 03. nov. 2020
}

Revista ALTERJOR

Grupo de Estudos Alterjor:Jornalismo Popular e Alternativo (ECA-USP)

Ano 10 Volume ol Edição 23 Janeiro-Junho de 2021

Avenida Professor Lúcio Martins Rodrig̉ues, 443, Cidade Universitária, São Paulo, CEP: 05508-020 


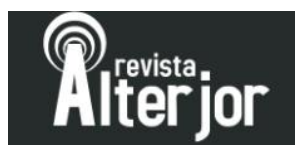

texto no jornal impresso Embarque no Direito e faço parte da Rede Jornalistas das Periferias e da Universidade Livre Grajaú (UniGraja) ${ }^{21}$.

Sempre tive um fascínio pelas mídias. Aos 7 anos de idade, li um exemplar do jornal "Notícias Populares". Meu pai tinha sido entrevistado sobre o assassinato cometido por um vizinho contra sua jovem noiva. O que chamou a atenção foi a narrativa do acontecimento no texto descrevendo o lugar em que eu morava com relevância. Foi a primeira vez em que me identifiquei no jornal.

Outro momento foi um protesto feito por estudantes, pais e professores em 1998 por melhores condições de estudo na EE Carlos de Moraes Andrade. A TV Bandeirantes cobriu o protesto e entrevistou alunos. A reportagem provocou a interdição das salas de madeira e o governo estadual precisou construir novos espaços de alvenaria.

Mais do que episódios pontuais, o que corroborou essa possibilidade no meu imaginário foram as idas semanais à casa de minha avó paterna, também no Grajaú. Minha tia era assinante de várias revistas, entre elas a Veja, que eu aprendi a ler semanalmente. A vocação foi alimentada com o acesso ao primeiro computador na família, à primeira máquina fotográfica (e a filmes fotográficos) e, finalmente, à primeira câmera digital, que permitiram experimentar "ensaios" fotográficos e até pequenos vídeos em meio à rotina da escola, às atividades sociais com a pastoral da juventude católica e ao trabalho no comércio, que comecei aos 14 anos de idade.

Sou filho de migrantes que chegaram a São Paulo em 1983, vindos ele do semiárido baiano e ela da zona da mata mineira para trabalhar, respectivamente, na indústria metalúrgica e como empregada doméstica. Entendo que, apesar das barreiras impostas pelas questões de classe e da ausência do Estado nesse território, o fato de sermos identificados como brancos em um espaço de maioria negra permitiu se esquivar do filtro do racismo pelos quais tantos outros do mesmo espaço foram submetidos.

${ }^{21}$ Disponível em: http://facebook.com/unigraja. Acesso em 03 nov. 2020. 


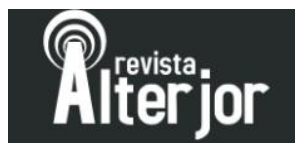

Todos esses fatores (o acesso a conteúdos, o racismo estrutural e o interesse individual na área) foram primordiais para, aos 18 anos, ingressar no curso de Jornalismo. A escolha por uma instituição privada denotava a certeza de que a universidade pública era inalcançável no contexto da época.

Para além das relações pessoais, a faculdade causou grande impacto por conta da quantidade de conteúdos e a falta de bagagem. Além de espaço de estudo, as viagens no transporte coletivo propiciaram reflexões sobre uma possível entrada no mercado de trabalho e das próprias origens.

Em 2007, iniciei um estágio no Instituto de Defesa do Consumidor (Idec), que permitiu ampliar a ideia de luta coletiva e conquista de direitos que eu vivenciei na prática na adolescência católica. No mesmo ano, iniciei um estágio em uma editora jornalística que mantinha um portal com atualização diária de notícias sobre o mercado de finanças e tecnologia da informação. No início de 2008, estagiei em um site de anúncio de imóveis alimentando a área de conteúdos sobre mercado imobiliário. E no mesmo ano, ainda estudante, comecei a trabalhar como repórter em uma revista de tecnologia e negócios

Todas essas experiências, participando de coletivas de imprensa ou cobrindo temas completamente novos e alheios à minha realidade, as trocas com editores e colegas de profissão bem como os questionamentos e comparações de diferentes realidades ampliaram ainda mais meu olhar sobre o jornalismo ao mesmo tempo em que fermentavam o que estava por vir: a Periferia em Movimento.

O projeto, que nasce desses embates e desejos, ganhou vida em uma troca de mensagens em 2008 com as colegas de faculdade Aline Rodrigues e Sueli Reis. As conversas amadureceram até que, no início de 2009, começamos a pesquisa que resultaria na Periferia em Movimento: a história do Evento pela Paz, uma mobilização de artistas, educadores, religiosos e outros agentes contra a violência e pela cultura de paz no Grajaú. Sem roteiro, acompanhamos os preparativos do Evento, entrevistamos organizadores e escolhemos personagens para compor a história. Foram mais de 30 


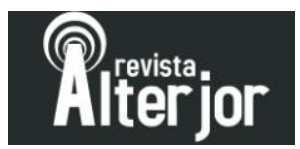

horas de gravação que resultaram em um vídeo de 20 minutos. Todos tinham uma história para contar. ${ }^{22}$

O que era para ser apenas um TCC sem perspectiva de continuidade transformou-se em algo duradouro quando artistas, coletivos e movimentos começaram a enviar conteúdos para divulgar ações de seus territórios no blog que criamos para falar de bastidores das gravações Sem referências na internet, demos continuidade ao projeto com a promoção de debates em 2010, com patrocínio do Programa VAI da Secretaria Municipal de Cultura de São Paulo. E em 2011, novamente com fomento dessa política pública, promovemos oficinas de audiovisual que resultaram em sete curtasmetragens ${ }^{23}$.

Em 2012, focamos em atividades culturais nas periferias. Enquanto a renda de Aline e eu era mantida por trabalhos freelance, nós circulávamos por mais tempo em nossos próprios territórios, identificando fontes e esboçando pautas. A presença física nos locais fez com que a gente ficasse conhecido por quem estava na linha de frente pela garantia de direitos. E essa presença começou a ser vista como motivo de ação. Em 2013, por exemplo, cobrimos um ato do movimento Passe Livre na região que terminou com a detenção de mais de 20 pessoas pela polícia e a ida de vários manifestantes para a porta da delegacia. Eu fui "escalado" pelas pessoas que participavam do ato para dialogar com representantes da imprensa do centro que acompanha a manifestação.

Isso demonstra que fazer jornalismo de quebrada é fazer de volta a travessia na cidade. Ao sair da periferia, atravessar a ponte com objetivo de estudar e experimentar o fazer jornalístico convencional, não é possível voltar da mesma forma. E ao voltar, nos remodelamos enquanto sujeitos. E a desconstrução do fazer por si só é uma atividade pedagógica em via de mão dupla. Aprendemos ao explicar aos demais aquilo que pretendemos fazer ao mesmo tempo em que desconstruímos a visão daquele sujeito sobre o que é jornalismo. Essa desconstrução se estende quando nos encontramos no ônibus, no banco ou em atividades em que não estamos "a trabalho".

\footnotetext{
${ }^{22}$ Disponível em: http://periferiaemmovimento.com.br/grajau-na-construcao-da-paz/. Acesso em 03 nov. 2020.

23 Disponível em: http://periferiaemmovimento.com.br/oca-oficina-de-cinema-amador/. Acesso em 03 nov. 2020
}

Revista ALTERJOR

Grupo de Estudos Alterjor:Jornalismo Popular e Alternativo (ECA-USP)

Ano 10 Volume ol Edição $23 \quad$ Janeiro-Junho de 2021

Avenida Professor Lúcio Martins Rodriģues, 443, Cidade Universitária, São Paulo, CEP: 05508-020 


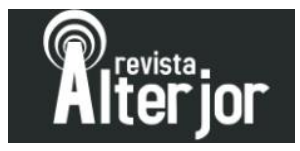

Colocamos a vivência no cotidiano periférico, nas travessias da cidade e o conhecimento e experiência adquiridos no meio jornalístico para edificar essa “organização". Fora do padrão do mercado, a dificuldade imediata é de sustentabilidade financeira. Se não há glamour de um lado, por outro abunda precariedade. Romper esse ciclo, assim como a pobreza estrutural que mantém as populações na periferia do sistema, é o maior desafio. Além disso, há a necessidade de separar a coletividade dos indivíduos, o que temos feito com muito apoio externo..

Enquanto jornalista de quebrada, sou sujeito comunicacional mas também sujeito periférico - no sentido de Tiaraju Dandrea (2013), é o morador ou a moradora de periferia que se entende enquanto tal e passa a agir politicamente para transformar sua realidade.

\subsection{ALINE RODRIGUES: A PREOCUPAÇÃO COM O RETORNO ÀS FONTES}

Me chamo Aline Rodrigues, tenho 35 anos e sou moradora do Campo Limpo, zona Sul de São Paulo. Sou mãe, jornalista, educomunicadora e cofundadora da Periferia em Movimento. Também sou coidealizadora da Rede Jornalistas das Periferias e integrante do Fórum Comunicação e Territórios. Represento a Periferia em Movimento na comissão organizadora do Prêmio Jornalístico Vladimir Herzog e no Fórum Permanente de Debate e Reflexão Sobre o Sistema Penitenciário e Carcerário.

Desde 2009, pela Periferia em Movimento, elaboro, coordena e realizo encontros de aprendizagem entre palestras, oficinas, rodas de conversa e cursos nas temáticas de jornalismo periférico, direitos humanos, culturas, identidades, narrativas e memórias. Também atuo na incidência política pelo campo do jornalismo de quebrada.

Fazer jornalismo de quebrada é pulsante. É nunca se ver na zona de conforto. É olhar atento para seguir coerente na produção de conteúdo jornalístico a partir do que realmente importa ser apurado, registrado, publicado e distribuído de acordo com o que o público quer e precisa saber. Esse é um compromisso fundamental do jornalismo.

Almejamos reconhecimento da relevância e manutenção da nossa credibilidade prioritariamente dados pela população periférica. Incidência em outras camadas da sociedade são importante para fomentarmos de forma mais efetiva uma sociedade livre 


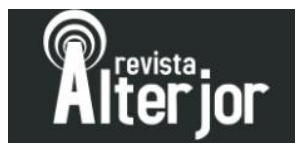

de racismo, machismo e LGBTfobia, mas se o conteúdo da Periferia em Movimento não dialoga com quem mora em regiões periféricas e vive as consequências da não garantia dos direitos básicos e do silenciamento comum de suas narrativas, não há porque seguir ou, ao menos, é preciso repensar as práticas ao destoar deste propósito.

O meu fazer jornalístico, que deságua na minha atuação na Periferia em Movimento, é alimentado inevitavelmente por minhas vivências. Pisar no mesmo chão que retratamos é princípio básico, assim como a escuta ativa de cada fonte, porque o meu olhar sobre o território não é o mesmo que o de outras pessoas.

Aos 14 anos, fiz minha primeira produção jornalística. Escrevi um breve texto no jornal da igreja católica que frequentava no Campo Limpo. O texto retratou a mobilização feita por crianças e professoras da EMEI Carlos de Laet, localizada no Parque Arariba, para conscientizar moradoras e moradores sobre a importância de preservarmos a praça no bairro, não jogando lixo no chão e no rio que ainda hoje resiste em meio ao concreto. Desde lá, me responsabilizei por mostrar para as fontes o resultado da minha publicação. Entender se o registro feito retratava de fato seu movimento, sua luta, sua resistência, sua identidade - nessa primeira publicação, no caso, para as crianças que entrevistei.

O aprimoramento desse olhar e consciência desses cuidados ao atuar no jornalismo vem a cada passo dado. A cada nova pauta, a cada entrevista, os inúmeros aprendizados e o maior e melhor entendimento da força e das motivações das mobilizações sociais foram fazendo cada vez mais sentido.

Antes de poder me dedicar prioritariamente à Periferia em Movimento, foi importante também passar por outros fazeres dentro da área de comunicação. Fazer comunicação empresarial me deu compreensão de como atuam, refletem e se posicionam as empresas diante da sociedade. Quais motivações e estratégias as movem para cada ação que estabelece alguma relação com os territórios periféricos, em especial, onde instalam suas sedes, fábricas, operações de exploração de recursos naturais e humanos.

Compreendi que a Responsabilidade Socioambiental era mais encarada como algo que garantiria um melhor desempenho na Bolsa de Valores do que efetivamente 


\section{Preitior}

uma preocupação e respeito aos valores, tradições, identidades e garantia de direitos básicos dos moradores e moradoras do seu entorno, muitas vezes, também seus funcionários e funcionárias.

As ferramentas, os fluxos de organização, as referências desses espaços que passei inevitavelmente influenciam no meu fazer jornalístico na Periferia em Movimento, mas nem tudo se aplica e tudo que ainda trago na memória desses tempos, traduzo como recurso que tenho para usar o que nos cabe. As narrativas que quero e queremos enquanto Periferia em Movimento registrar e fomentar ser levado em conta nas decisões políticas e nas construções de políticas pública.

E minha atuação sozinha não diz muito. A força está na ação conjunta. O nosso jornalismo reflete quem nos propomos a retratar. Falamos de movimentos autônomos, independentes, que surgem das periferias e se propõem a oferecer algo prioritariamente para as periferias e atuar em rede com outras iniciativas para fazer melhor, para se fortalecer e ter mais condições de resistir.

\subsection{LAÍS DIOGO: PORTADORA DO LEGADO}

Eu me chamo Laís Diogo, tenho 22 anos, moro no Grajaú (Extremo Sul de São Paulo) e sou produtora cultural na Periferia em Movimento. Antes de trabalhar na iniciativa, participei de oficinas enquanto adolescente. Desde 2015, comecei a me envolver diretamente nas produções do, na época, coletivo.

Nunca senti desejo de estudar Jornalismo ou alguma área de comunicação. Sempre fui muito ligada às questões sociais e de militância. Porém, quando conheci a Periferia em Movimento, fiquei apaixonada pelo trabalho, pelo afeto entre os integrantes, pelo amor que tinham pelo que faziam, e o que me fez despertar a pensar essa comunicação foi a defesa crucial de falar do Grajaú para o Grajaú. Isso me fez enxergar coisas que eu nunca tinha visto dentro da minha casa.

Ainda estava no ensino médio e já tinha decidido estudar serviço social, ao mesmo tempo em que decidi que queria ser comunicadora para falar o que estava acontecendo na minha quebrada. A partir do momento que eu me entendi como uma 


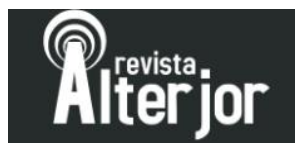

pessoa que comunica, que trata direta e indiretamente do direito à comunicação no meu território, eu me entendi como uma potência desse lugar.

Por meio da Periferia em Movimento, pude conhecer meus próprios vizinhos, entender as angústias de outras adolescentes negras que não se sentiam representadas em uma mídia hegemônica, racista, homofóbica, transfóbica, gordofóbica. Uma mídia branca, e machista, que tenta vender uma noção de família, de padrão de vida, de relacionamento, que para mim enquanto mulher negra da periferia sempre foi negado.

Trabalhar com a Periferia em Movimento me mostrou que é possível ser representada, fazendo o que se gosta perto de casa. É possível ser autônomo, ter 22 anos e pensar numa carreira de comunicação para além das universidades, e isso mesmo com todos os perrengues de uma vida "normal", com todas as angústias de um País e de uma mídia que continuam perpetuando nossas mortes.

Apesar de sempre ter participado de grêmios estudantis e reivindicar, no mesmo nível sempre fui silenciada, e isso foi de encontro ao fazer da Periferia em Movimento, que tem como base entender as demandas do território e, a partir dessas demandas, produzir conteúdo de qualidade, oficinas, cursos. Tudo isso com o intuito de que jovens e adolescentes que passam por esses encontros tenham o mínimo possível de consciência sobre potências, para reverter um processo histórico da mídia que nos marginaliza, nos coloca nas caixinhas dos subempregos e nas páginas de violência.

A partir disso, eu defino a Periferia em Movimento como um potencial que desperta potências. Nosso trabalho, para além de jornalismo, está ligado diretamente com o despertar de direitos e de noção territorial. A gente escreve, produz e ensina para nós mesmos. É uma roda que não para de girar. Enquanto falamos dos direitos básicos, lutamos por nós mesmos, para garantir o que deveríamos ter enquanto sujeitos dignos de direitos. É um movimento que não para: gera conhecimento, desconstrução, amor e uma visão de vida melhor.

Com o meu olhar dentro da Periferia em Movimento, construo um futuro melhor para as meninas negras da minha quebrada ao falar das minhas dores que não são somente minhas, dos amores que não são somente meus. Ao mesmo tempo, a gente se complementa nas diferenças, se entende porque o público também é diverso. 


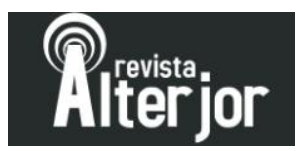

A consolidação da Periferia em Movimento enquanto uma produtora de jornalismo de quebrada já é o futuro: é abrir as portas do Grajaú para receber o que é nosso por direito agora da ponte pra cá. Para isso, a gente pensa na ancestralidade como ponto de partida. Tem gente colocando água no feijão há muito tempo para que as gerações futuras sejam fartas de conhecimento e para que os nossos continuem se vendo nos jornais, até um dia em que pretos não sejam estatísticas de morte e violência, as mulheres deixem de morrer nas mãos dessa nação machista e a população LGBTQ+ possa andar tranquilamente sem medo das violências causadas pelo Estado.

\subsection{CAMILA LIMA: MULTIPLICANDO POSSIBILIDADES}

Eu me chamo Camila Lima Cerqueira, tenho 28 anos, sou cria da periferia da zona Sul de São Paulo e, na Periferia em Movimento, sou responsável pelas mídias sociais.

Minha história com o jornalismo vem desde a infância. Sempre fui uma criança muito sonhadora e um tanto quanto estranha por gostar de ver o jornal na TV ao invés de outras programações. Eu amava ver desenhos na TV Globinho, mas me sentia muito bem vendo o jornal do meio dia.

Eu vim de uma família totalmente desestruturada. Passei por abandono pelos pais e, devido a isso, fui criada por minha avó materna e uma tia. Ambas pobres e de vidas muitos sofridas, de muita luta, que quando ouviam a Camila criança falar que seria jornalista tinham como primeira reação a seguinte fala: "Jornalismo não é para gente pobre como nós. Somente filho de rico faz jornalismo. Somente filho de rico aparece na TV". Como uma boa teimosa, respondia que não era filha de rico, mas seria jornalista.

Aquela criança sonhadora, que desde cedo foi entendendo a dinâmica da vida periférica, cresceu e se deparou com a realidade do pré-vestibular, as dificuldades de uma vaga na universidade pública e a falta de dinheiro para estudos em universidade particular. Mas tinha como meta o Jornalismo. Troquei força de trabalho em troca de bolsa em cursinho, prestei vestibular em diversas universidades públicas, passei após

\footnotetext{
Revista AL TERJOR

Grupo de Estudos Alterjor:Jornalismo Popular e Alternativo (ECA-USP)

Ano 10 Volume ol Edição $23 \quad$ Janeiro-Junho de 2021

Avenida Professor Lúcio Martins Rodrig̉ues, 443, Cidade Universitária, São Paulo, CEP: 05508-020
} 


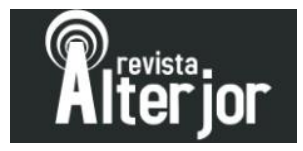

muita luta na Unesp. Esse foi o momento que me senti muito feliz por ser capaz de passar no vestibular, mas fiquei triste também pois não tinha dinheiro para concluir a matricula e os demais quesitos, pois a universidade era em outra cidade.

Nesse período eu conheci coletivos da minha região que abordavam muitas das minhas vivências, que entendiam e lutavam por essas causas. Foi neste momento de conhecer e reconhecer pessoas semelhantes que surgiu a vontade de desenvolver um projeto na minha quebrada e para os meus que girasse em torno do Jornalismo. Acabei conhecendo a Periferia em Movimento, que já desenvolvia jornalismo de quebrada há algum tempo na região e contemplava meu desejo.

Em 2019, me inscrevi em um curso que foi desenvolvido no espaço de jornalismo da produtora e, neste momento, em contato com toda a equipe, pude aprender mas também mostrar o que eu já sabia e desenvolvia por estágios que eu já tinha passado. Desde este contato, a Periferia em Movimento ficou de olho em meu potencial. Tentamos desenvolver algum projeto desde então, sem sucesso, até que no segundo semestre de 2020 fui chamada para participar das melhorias de redes sociais da iniciativa. Como já tinha estagiado em um outro veiculo, eu pude trazer um outro olhar para somar aos projetos já iniciados da equipe.

Atualmente eu faço parte da equipe de distribuição das redes sociais. Alimento as principais plataformas sociais (Instagram, facebook, etc.) e aprendo muito com essa equipe experiente. Além da função que faço parte oficialmente, a equipe me dá a oportunidade de criar pautas e matérias, e exercer o jornalismo para além das redes.

Com isso, consigo aprender com os meus e, mais do que isso, alimentar o sonho de outras tantas possíveis Camilas que tenham na quebrada. $\mathrm{O}$ jornalismo veio na minha vida não por acaso, mas sim para que por meio dele eu possa inspirar tantos outros em suas batalhas diárias. 


\section{DAQUI PRA FRENTE}

Criar espaços para que outras narrativas possam fluir é também possibilitar a geração de um outro imaginário social coletivo. Por isso, a importância das mídias e do jornalismo - que ainda não dão conta de todas as demandas da população periférica. E a Periferia em Movimento tem isso em perspectiva.

Segundo a pesquisa Atlas da $\mathrm{Notícia}^{24}$, feita pelo Instituto para o Desenvolvimento do Jornalismo em parceria com o Volt Data Lab, mais de 70 milhões de brasileiros (35\% da população) não possuem registro de atividade jornalística impressa ou digital em seus territórios. Apesar de o Estado de São Paulo ser campeão em mídias locais no País, há uma distorção na produção e circulação entre centro e periferias, criando uma escassez de informações em contexto local.

Isso ganha notoriedade no "Mapa do Jornalismo Periférico: Passado, presente e futuro" 25 , um estudo apresentado em 2019 pelo Fórum Comunicação e Territórios. Em 2019, o grupo mapeou 97 realizadores comunicativos que estão e atuam a partir de regiões periféricas da cidade de São Paulo, entre pessoas, coletivos ou organizações sociais e culturais. Segundo a pesquisa, no início dos anos 1990, jornais impressos, fanzines e rádios já disputavam o direito à comunicação nos territórios periféricos, mas o movimento teve um boom a partir de 2012, com a criação de novas 36 iniciativas.

Possibilitar visibilidade e quebrar estereótipos sobre a vida nas quebradas é a principal motivação para existência das iniciativas de comunicação nas periferias de São Paulo. E, como missão, o viés formativo que trabalha o pensamento crítico e a criação de um novo imaginário aparece ao lado da abordagem cultural e do recorte de raça, gênero, classe e sexualidade.

Porém, manter esse trabalho profissional é chave para entender os limites da produção jornalística nas quebradas. Mais de $80 \%$ dos entrevistados na pesquisa têm

\footnotetext{
${ }^{24}$ Disponível em: https://www.atlas.jor.br/. Acesso em 03 nov. 2020

25 Disponível em: http://periferiaemmovimento.com.br/apos-30-anos-de-luta-comunicadores-dasquebradas-ainda-passam-perrengue-pra-trampar/. Acesso em 03 nov. 2020
} 


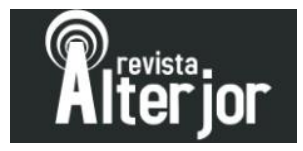

conteúdo autoral, e apenas 33\% publicam conteúdos diariamente. Apesar da força, $80 \%$ das pessoas envolvidas nas iniciativas têm outro trabalho como fonte de renda principal.

Por isso, para se manter viável a médio e longo prazo, a Periferia em Movimento vislumbra na construção e fortalecimento de redes de apoio mútuo para elaboração de políticas públicas no campo da comunicação e, quando possível, gestão de um mercado solidário, baseado em outros termos, para subsistência de iniciativas como essa.

Ao mesmo tempo, é crucial seguir nos territórios, rumo às margens ainda não alcançadas, pisando no mesmo barro que as populações que seguem marginalizadas pela sociedade estão neste momento, narrar suas histórias e reelaborar imaginários coletivos comuns em que os direitos sejam garantidos - seja por nossa própria ação, seja reinventando formas ou potencializando novos jornalistas de quebrada.

Mais do que a produção contínua de conteúdos jornalísticos, a Periferia em Movimento segue como laboratório de experimentações no jornalismo, em constante metamorfose, acompanhando os movimentos de uma sociedade cada vez mais fluída, mas que perpetua desigualdades.

\section{REFERÊNCIAS}

D’ANDREA, Tiarajú Pablo. A formação dos Sujeitos Periféricos: Cultura e política nas periferias de São Paulo. Doutorado (Tese). Departamento de Sociologia, FFLCH-USP. São Paulo: 2013.

FELTRAN, G. Transformações sociais e políticas nas periferias de São Paulo. In: KOWARICK, L.; MARQUES, E. (Org.). São Paulo: novos percursos e atores. São Paulo: Editora 34; Centro de Estudos da Metrópole, 2001. 400 p.

KOWARICK, L. Viver em Risco: sobre a vulnerabilidade socioeconômica e civil. São Paulo: Editora 34, 2009. 320p.

MARTINS, R. APA Bororé: Subsídios a implantação - Praticando Geografia com a Teoria do Geossistemas. Bacharelado (Trabalho de Conclusão de Curso). Departamento de Geografia, FFLCH-USP. São Paulo: 2003.

RIBEIRO, E. M. A política de imigração no $1^{\circ}$ reinado: os núcleos coloniais de Itapecerica e Santo Amaro. In: MARTINS, R. APA BORORE: Subsídios a implantação - Praticando Geografia com a Teoria do Geossistemas. Bacharelado (Trabalho de Conclusão de Curso). Departamento de Geografia, FFLCH-USP. São Paulo: 2003.

SANTOS, Milton. O dinheiro e o território. GEOgraphia, Rio de Janeiro, Ano 1. n. 1, p. 7-13, 1999. 


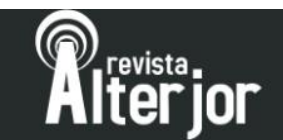

SÃO PAULO. Governo do Estado. Lei Estadual n.o 1.172/76. São Paulo, 1976.

SÃO PAULO. Prefeitura Municipal. Infocidade: Estimativas da população em domicílios em favelas no ano 2000. São Paulo, 2015. Disponível em: <http://infocidade.prefeitura.sp.gov.br/htmls/9_estimativas_de_populacao_e_domicilios_em_20 00_324.html>. Acesso em 20 ago. 2015.

SÃO PAULO. Prefeitura Municipal. Infocidade: Listagem de Favelas do Município de São Paulo no ano 2000. São Paulo, 2015. Disponível em: <http://infocidade.prefeitura.sp.gov.br/htmls/9_distribuicao_das_favelas_2000_516.html>.

Acesso em 03 nov. 2020.

SÃO PAULO. Prefeitura Municipal. Infocidade: Estimativas de domicílios em favelas - 2008 a 2014. São Paulo, 2015. Disponível em: <http://infocidade.prefeitura.sp.gov.br/htmls/9_estimativas_de_domicilios_em_favelas_2008_1 062 4.html>. Acesso em 03 nov. 2020.

SÃO PAULO. Prefeitura Municipal. Infocidade: População censitária e projeções populacionais. São Paulo, 2015. Disponível em: <http://infocidade.prefeitura.sp.gov.br/htmls/7_populacao_censitaria_e_projecoes_populac_200 8_1 0489.html>. Acesso em 03 nov. 2020.

SÃO PAULO. Prefeitura Municipal. Infocidade: População recenseada e taxas de crescimento. São Paulo, 2015. Disponível em: <http://infocidade.prefeitura.sp.gov.br/htmls/7_populacao_recenseada_e_taxas_de_crescime_19 80_10747.html >. Acesso em 03 nov. 2020.

SÃO PAULO. Subprefeitura da Capela do Socorro. Aspectos Demográficos. São Paulo, 2015. Disponível em:

<http://portal.prefeitura.sp.gov.br/subprefeituras/spcs/dados/aspectos_demograficos/0001>. Acesso em 03 nov. 2020.

SÃO PAULO. Subprefeitura da Capela do Socorro. Aspectos Físico-territoriais. São Paulo, $2015 . \quad$ Disponível em: <http://portal.prefeitura.sp.gov.br/subprefeituras/spcs/dados/aspectos_fisicos/0001>. Acesso em 03 nov. 2020.

SOUZA, J. S. Jornalismo de Quebrada e as Representações das Periferias Paulistas. Graduação, FAPCOM. São Paulo: 2015.

SILVA, E. A. Governar o ingovernável: gestão da irregularidade urbana em áreas de mananciais em São Paulo. Doutorado (Tese). Departamento de Sociologia, FFLCH-USP. São Paulo: 2011. 